account of the notices that have appeared in NATURE (vol. xxi. pp. 330, 372, and vol. xxii. p. 77) and in Comptes rendus (xc. 62226), this note would be needless, were it not that some may regard these ashes as of recent origin.

Microscopically the material (already described by Prof. Delesse) is seen to be decomposed to a considerable extent. The materials evidently filled an old crater, and have been subjected to secondary action, so that of the original constituents only the feldspar and augite are left. The other constituents are the results of the alteration of this andesitic (probably) débris. No trace of recent volcanic material conld be found in that examined by me. In no sense can these ashes be called a recent product; they have simply been transferred from one place to another. The transfer is recent, but the ashes have for ages been at or near the surface of the earth.

Museum of Comparative Zoology, Cambridge, Mass., U.S.A., June 30

\section{Large Meteor}

ON Friday evening last, July 9 , at $9 \mathrm{~h}, 45 \mathrm{~m}$., I saw a very fine meteor about equal in brightness to Venus at her maximum, moving very slowly from nearly west to south-west. I did not see its origin. It passed about $4^{\circ}$ above Spica, and disappeared soon afterwards, as nearly as I could estimate, in altitude $16^{\circ}$ and azimuth $50^{\circ}$ west of S. Its apparent course was only slightly inclined to the horizon, approaching it at an angle of about $\mathbf{I}$ in 10

Its apparent angular velocity was about $\delta^{\circ}$ in a second, its light yellowish till the moment of extinction, when it became blue and fainter, and disappeared without any sign of explosion. Its course was somewhat wavy, and the trail it left behind it very evanescent. My latitude and longitude was $51^{\circ} 25^{\prime}$ and $0^{\circ} \mathrm{I}^{\prime} \mathrm{W}$.

Coleby Field, Wimbledon, July I4

\section{Ball Lightning}

ON Saturday night, the 17 th inst., an instance of this form of lightning came under my observation.

The day had been hot, the thermometer registering a temperature of about $7 \mathrm{I}^{\circ} \mathrm{F}$. in the shade during the middle of the day, which was bright and clear. In the evening, however, a curious haze or mist spread rapidly over the landscape, while the temperature had fallen to about $68^{\circ} \mathrm{F}$. This haze was very much denser and more analogous to the smoke-fog of a town than I have ever observed in the country at this time of year, yet the air did not seem particularly damp or chill.

About 9 p.m. frequent flashes of sheet-lightning occurred, with rumblings of distant thunder at intervals, both of which continued more or less up to midnight, about which time, the mist having somewhat cleared off, I saw when returning home, apparently about a quarter of a mile ahead, a ball or globe of fire of considerable size descend slowly from the clouds, and when near to or touching the earth suddenly disappear, its disappearance being accompanied by two slight but quick concussions, which may have been an explosion and its echo. The fire-ball could not have been visible more than five or six seconds. I cannot ascertain that any damage was done by it.

As this somewhat rare and curious phenomenon seems to be manifesting itself at this period, accompanying the thunderstorms we are having (see NATURE, vol. xxii. p. I93), may I be permitted to suggest that those interested in electrical science should be on the alert to observe any repetition of the occurrence with its concomitant circumstances?

W. F. SMITH

Sutton Valence, Kent

E. M. F. should read Prof. Ayrton's Sheffield lecture on "Electricity as a Motive Power" (see NATURE, vol. xx. p. 568); any decent text-book-Noad's, for example-will tell of the older attempts of Jacobi to propel boats by electricity.

\section{THE RECENT EXPLOSIONS}

ATHOUGH it is difficult to say anything new on the subject, or give instructions more effective than such as have been given over and over again, still the recent remarkable and destructive explosions in London, Wolverhampton, and Monmouthshire seem to call for some remarks at our hands.

Two serious explosions of gas following close on each other, in the streets of large towns, announce to every one that the difficulties of supplying gas to large numbers of consumers have not been completely overcome.

The special feature in the London accident was the occurrence of a series of explosions, at first at nearly regular, and then at increasing intervals, along the gas main. The first explosion blew out the "cap" of the main with great violence; the rush of heated air, doubtless mingled with more or less gas, in the other direction seems to have carried the flame-probably by a rapidly occurring series of small explosions - to a point at which a mass of explosive gas was again reached and fired. The mass of gaseous mixture fired in the second explosion appears to have been about equal to that in the first, but towards the close of the series either the gas became much more diluted with air, or the air became much more charged with gas. It seems just possible that vibrations propagated by the first explosion passed rapidly through a gaseous medium, consisting of much air and little gas, until they came in contact with a mass of gas and air, which they threw into rapid vibration, and so caused to explode. But from the experiments of Abel and others one would scarcely expect this to occur under the conditions which-judging from the evidence given at the inquest-appear to have existed.

A second point, illustrated more markedly by the Wolverhampton explosion, is the apparent readiness with which a soil may be charged with coal-gas and retain this gas for long periods of time. The passage of such gas into drain-pipes, and perhaps even into unfilled gas-mains, seems to be of ready occurrence.

Experiments might well be instituted by the gas companies to determine the power of soils for absorbing and retaining coal gas, and secondly, the conditions of diffusion of mixtures of gas and air through the walls of pipes of different materials. If it can be shown with certainty that the valve at the junction of the main in which the explosion occurred with the Howland Street main was absolutely impervious to gas, then the explosion may almost be regarded as proving the permeability of the material of gas mains to mixtures of air and coal-gas.

The practical lesson of the explosions is that some means of certainly determining whether a gas main does or does not contain gas must be found at once, and that this means must not be the application of a light to an opening in the main. The foreman who applied the fatal match said that the pressure gauge showed the absence of gas in the main ; but as the main contained a quantity of gaseous mixture at rest, and not flowing tbrough the pipe, the gauge could not be expected to indicate the presence of this mixture.

It is almost amusing to read of the simple astonishment of the two foremen when the fact was announced to them that mixtures of coal-gas and air are explosive: twenty or twenty-five years' experience in gas-works had failed to teach them this fact. Yet the lives of the inhabitants in the neighbourhood of Tottenham Court Road were practically in these men's hands for the last three or four months.

With regard to the Risca disaster, of a different and unhappily more fatal kind than the former, clouds of smoke are said to have accompanied the explosion which devastated the pits soon after midnight on Thursday last ( 15 th inst.), and we have it from the lips of a credible eyewitness that fused and coked coal-dust is found adhering to the timbers in those parts of the workings which have been already visited, though not so conspicuous as in some cases. In these respects therefore the recent explosion is only a repetition of similar events which have 